American Journal of Environmental Sciences 6 (3): 230-237, 2010

ISSN 1553-345X

(C) 2010 Science Publications

\title{
Toxicological Response of the Green Alga Chlorella vulgaris, to Some Heavy Metals
}

\author{
E. Afkar, H. Ababna and A.A. Fathi \\ Department of Biological Science, College of Science, King Faisal University, Saudi Arabia
}

\begin{abstract}
Problems statement: The disturbance of aquatic ecosystems provoked by heavy metals pollution from industrial and domestic sources, has as consequence the loss of biological diversity, as well as increased bioaccumulation and magnification of toxicants in the food chain. The aim of this study was to evaluate the effect of some heavy metals on some physiological activities of Chlorella vulgaris beyerinck with special references to metal bioaccumulation. Approach: Chlorella vulgaris Beyerinck was isolated from Al-Asfar Lake, Al-Hassa, Saudi Arabia. A standard initial inoculum of the isolated algae was inoculated to culture flasks. The culture flasks were supplied with various concentrations of Cobalt, Copper and Zinc ranging from $10^{-6}-10^{-9} \mathrm{M}$. At the end of the incubation period cultures were filtered and washed several times by distilled water for measurements the various experimental parameters. Results: The data show that the lower doses of the three tested metals had stimulatory effect in biomass yield of Chlorella vulgaris, whereas the higher doses were inhibitory depending on the type of the metal. The inhibitory effect of copper to the growth parameters of Chlorella vulgaris was more pronounced than other two tested metals. The total protein content, total carbohydrate and the total free amino acids of the tested green alga Chlorella vulgaris gradually decreased in a manner dependent on the metal concentration in the medium. On the other hand, bioaccumulation of cobalt, copper and zinc by Chlorella vulgaris cells were parallel to increasing the concentrations in the culture medium. Conclusion: The inhibitory and stimulatory effects of either of the used heavy metals depend on concentration. Different organisms, however, have different sensitivities to the same metal and the same organisms may be more or less damaged by different metals. The uptake of an element from the surrounding medium is seldom exactly proportional to the amount present in the water.
\end{abstract}

Key words: Bioaccumulation, Chlorella vulgaris, heavy metals, metabolism

\section{INTRODUCTION}

Many pollutants like pesticides, oil hydrocarbons, heavy metals as well as thermal and radioactive pollution can get into aquatic environments after direct or indirect release from industries, agriculture and households (Fathi et al., 2008). As an important group of these various chemical substances, heavy metals may be deposited into all ecosystems (Mutlak et al., 1979). The disturbance of aquatic ecosystems provoked by heavy metals pollution from industrial and domestic sources, has as consequence the loss of biological diversity, as well as increased bioaccumulation and magnification of toxicants in the food chain (Pena-Castro et al., 2004).

Microalgae are sensitive indicators of environmental change and, as the basis of most freshwater and marine ecosystems, are widely used in the assessment of risk and development of environmental regulations for metals (Levy et al., 2007). There are a remarkable number of investigations demonstrating the toxic effects of heavy metals on different species of algae (El-Sheekh et al., 2003; Osman et al., 2004; Fathi et al., 2005; Akira et al., 2005; Muwafq and Bernd, 2006; Anne et al., 2006).

Heavy metal constitutes a stress factor for many microbes where there concentrations increased as a consequence of a wide range of agricultural and industrial activities. De Filippis and Pallaghy (1994) although some of these metals are required for cell growth, the high concentrations of all metals exert toxic effects on metabolic machinery of algae. The phenomenon of the growth of algae subjected to heavy metals stress was clarified (Fathi and Falkner, 1997; Fathi, 2002; 2005; Fathi et al., 2008). The aim of this study was to evaluate the effect of some heavy metals

Corresponding Author: A.A. Fathi, Department of Biological Sciences, College of Science, King Faisal University, 31982-Al-Hassa, P.O. Box 55076, Saudi Arabia Tel: 0096557001682 
Am. J. Environ. Sci., 6 (3): 230-237, 2010

on some physiological activities of Chlorella vulgaris Beyerinck with special references to metal bioaccumulation.

\section{MATERIALS AND METHODS}

Organism and culture condition: Chlorella vulgaris Beyerinck was isolated from Al-Asfar Lake, AlHassa, Saudi Arabia. Isolation and purification was made by dilution and plating technique. The alga was grown in $250 \mathrm{~mL}$ flasks containing $100 \mathrm{~mL}$ Kuhl (1962) medium and incubated in an illuminated incubator (Precision, USA) at $22^{\circ} \mathrm{C}$ and irradiance at $150 \mu \mathrm{mol} \mathrm{m}{ }^{-2} \mathrm{sec}^{-1}$, provided by cool white fluorescent lamps set on 14:10 $\mathrm{h}$ photoperiod. All cultures were shaken twice daily to prevent cells from clumping.

Sterile technique determinations of pigment content: Chlorophyll a and b content were estimated in acetone extract according to Jeffrey and Humphery (1975). The content of the pigments fractions $(\mu \mathrm{g} \mathrm{chl}$ $\mathrm{mL}^{-1}$ algal suspension) was then calculated under consideration of the dilution factors.

Algal counting: Cell number was determined using a Hematocytometer Chamber. Hemacytometer $0.1 \mathrm{~mm}$ deep, having improved Naubauer ruling was used. One drop of the algal suspension was pipetted on the slide, covered and left for two minutes for algal settling. The mean counts of three replicates were taken into consideration and the data were given as cell $\mathrm{mL}^{-1}$ algal suspension.

Calculation of growth rate: The growth rate of the algal growth was calculated by the following equation (Nichol's, 1973):

$\mathrm{K}($ day $)=\left[3.322 /\left(\mathrm{t}_{2}-\mathrm{t}_{1}\right] .\left(\log \mathrm{N}_{2} / \mathrm{N}_{1}\right)\right.$

Determination of dry weight: A definite volume (100 mL) of algal suspension was filtered through weighted glass fiber (Schleicher and Schull, Germany). The cells, after being precipitated on the filter study, were washed twice with distilled water and dried overnight in an oven at $105^{\circ} \mathrm{C}$. Data were given as $\mu \mathrm{g} \mathrm{mL}^{-1}$ algal suspension.

Treatment: A standard initial inoculum of the isolated algae was inoculated to culture flasks $(500 \mathrm{~mL}$ each $)$ that contained $200 \mathrm{~mL}$ of sterile nutrient medium (Kuhl's medium). The culture flasks were supplied with various concentrations of Cobalt, Copper and Zinc ranging from $10^{-6}-10^{-9} \mathrm{M}$. At the end of the incubation period ( 7 days) cultures were filtered and washed several times by distilled water. At least three replicates for each sample and controls were used.

Biochemical analysis: The enthrone method (Roe, 1955) was applied for total carbohydrate estimation using fresh material and glucose as a standard. Total amino acid content was determined according to Moore and Stein (1948). Total protein was measured according to Lowery et al. (1951)

Metal uptake: For the analysis of metal contents, the cultures were centrifuged to harvest the algal mass (50 mL). The algal pellet was washed with $2 \mathrm{mM}$ EDFA for $10 \mathrm{~min}$. to remove surface-bound metal. After centrifugation the pellet was digested $5 \mathrm{~mL}$ mixture containing $\mathrm{HNO}_{3}(70 \%), \mathrm{H}_{2} \mathrm{O}_{2}(30 \%)$ and deionized water in 1:1:3 ratio (Bates et al., 1982). After digestion the samples were analyzed for metal content with a Perkin-Elmer atomic absorption spectrophotometer.

Calculation of bioaccumulation factor: The bioaccumulation factor defined by (Brooks and Rumsby, 1965) is the ratio of concentration of an element in dry plant biomass and in the water.

Statistics: Results were tested by one-way Analysis Of Variance (ANOVA). ANOVA effects and treatments differences were considered significant when $\mathrm{p}<0.05$.

\section{RESULTS AND DISCUSSION}

It is well known that algal cells exposed to heavy metals may suffer serious morphological and biochemical alterations (Rocchetta et al., 2006). The results of this investigation show that the inhibitory and stimulatory effects of either of the used heavy metals depend on concentration.

The bioassay results as illustrated in Fig. 1 showed clear differences in pigments content (Chlorophyll a and b) of algal cells between control and treated ones when algae were exposed to different concentrations of the three tested metals. The pigments content gradually increased in the culture supplemented by concentration $10^{-9} \mathrm{M}$ during exposure periods, whereas other concentrations $\left(10^{-8}-10^{-6} \mathrm{M}\right)$ cause a clear reduction in the pigments content of Chlorella vulgaris. The same effect was observed with respect to growth rate as another indicator of algal growth as shown in Fig. 2. The growth rates decreased in respect of increasing metals concentration more than $10^{-9} \mathrm{M}$. Generally, the 


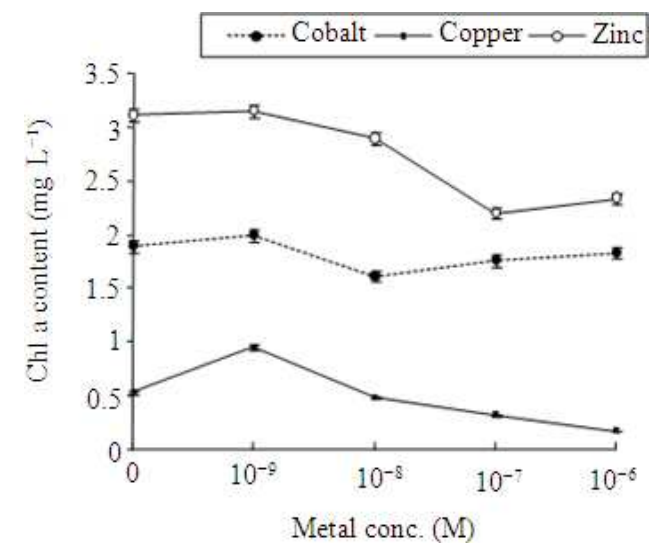

(a)

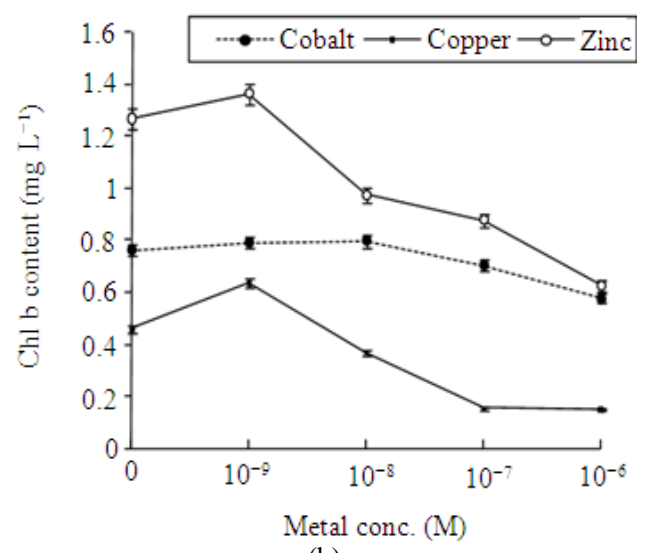

(b)

Fig. 1: Effect of various concentrations of cobalt, copper and zinc on pigments content ( $\mathrm{Chl} \mathrm{a}$ and $\mathrm{b}$ ) of Chlorella vulgaris after 7 days incubation period. Vertical bars indicate $\mathrm{SE}, \mathrm{n}=3$

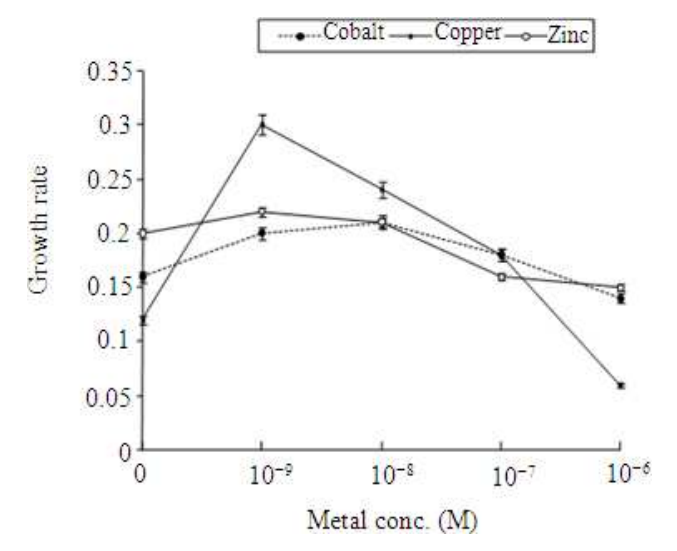

Fig. 2: Effect of various concentrations of cobalt, copper and zinc on growth rate of Chlorella vulgaris after 7 days incubation period. Vertical bars indicate $\mathrm{SE}, \mathrm{n}=3$ results shows that the low dose $\left(10^{-9} \mathrm{M}\right)$ of the three tested metals had stimulatory effect in biomass yield of Chlorella vulgaris, whereas the higher doses were inhibitory depending on the type of the metal. The total cell death occurred at concentrations $10^{-5} \mathrm{M}$ of copper and at $10^{-4} \mathrm{M}$ of cobalt and zinc (data not shown). The results also show that the inhibitory effect of copper on the growth rate and pigments content is more pronounced than for the other two tested metals two tested metals. These findings are in agreement with several previously published data (El-Sheekh et al., 2003; Osman et al., 2004; Fathi et al., 2005; Muwafq and Bernd, 2006; Romera et al., 2007; Cecilia et al., 2007; Deng et al., 2007).

Regards to the stimulatory or inhibitory effect of cobalt showed on this investigation, the present results are in agreement with those obtained by El-Naggar et al. (1999) who found that a lower $\mathrm{Co}^{2+}$ concentration (0.01 ppm) stimulated growth of Nostoc muscorum, while it showed a non-significant effect on Calothrix fusca growth. However, higher $\mathrm{Co}^{2+}$ concentrations were inhibitory for both organisms. On the other hand, growth promotion at low $\mathrm{Co}^{2+}$ concentrations may be due to $\mathrm{Co}^{2+}$ substitution for $\mathrm{Zn}^{2+}$ in some metalloenzymes in vitro and in vivo (El-Sheekh et al., 2003; Osman et al., 2004). Moreover, high concentrations of cobalt were inhibitory for pigment content of tested alga. These results are in agreement with those obtained by El-Naggar et al. (1999) who reported inhibition of chlorophyll biosynthesis as a result of $\mathrm{Co}^{2+}$ treatment. The mechanism proposed for this inhibition is the replacement of magnesium in the chlorophyll molecule. In this regard, De Filippis et al. (1981) reported that reduction of chlorophyll a content is a common symptom of heavy metals toxicity.

The stimulatory effect of copper recorded in this study with lower concentrations $\left(10^{-9} \mathrm{M}\right)$ can be accounted for either as a result of algal requirement of this element in metabolic processes or explained by production of some organic compound which decreases metal toxicity. Albergoni et al. (1980) and Rijstenbil et al. (1998) suggested that some of the algae capable to produce metal binding compounds there from get the ability to bind and sequester copper ions in the cytoplasm and reduce toxicity. On the other hand, the toxic effect of copper at higher concentrations $\left(10^{-7}\right.$ and $\left.10^{-6} \mathrm{M}\right)$ detected in the present study may be due to the oxidative potential of copper (II) that causes reduction of chlorophyll and decrease of oxygen evolution rates and depletion of ATP by inhibition of 
enzymes (nitrate reductase and alkaline phosphatase) which are involved in nitrate and ammonia cellular metabolism (Muwafq and Bernd, 2006).

The inhibitory effect of the zinc on the studied growth parameters at higher doses depended on their concentration in the culture medium. Fisher and Jones (1981), who reported that low $\mathrm{Zn}^{2+}$ levels enhanced the total chlorophyll in Asterionella japonica. Prassad and Prassad (1987) found that heavy metals inhibit the enzymes that are responsible for the chlorophyll (che) synthesis. De Filippis and Pallaghy (1994) reported that toxicity of $\mathrm{Zn}$ results from their binding to $\mathrm{SH}$ groups and disruption of enzyme structure (Omar, 2002). On the other hand, $\mathrm{Zn}$ does not directly accelerate the formation of reactive oxygen species due to its redox inertness and it, therefore, exerted comparatively less stress on the test organism (Tripathi and Gaur, 2006).

The data of Fig. 3 show that the total protein content of the green alga Chlorella vulgaris gradually decreased in a manner dependent on the metal concentration in the medium. The data also shows that all the three metals affected negatively the total protein content at higher doses. On the other hand, the supplementation of copper and zinc by concentration $10^{-9} \mathrm{M}$ increases the total protein content as compared to the control. However, no marked change in total protein content occurred in cells of Chlorella vulgaris which exposed to cobalt. It could be suggested that accumulation of protein at low heavy metal concentrations may be one of the ways through which the algae can abolish their toxic effects, or to increase respiration leading to the utilization of carbohydrate in favor of protein accumulation (Osman et al., 2004). Whereas, the suppression of protein accumulation may be attributed to shortage of carbon skeleton results from low photosynthetic rate. Such results are in accordance with those of Fathi et al. (2000). However, some authors (Osman et al., 2004; Tripathi and Gaur, 2006; Barbara and Michael, 1994) reported that the toxic action of heavy metals on the enzymatic reactions responsible for protein biosynthesis.

The total carbohydrates content of Chlorella cultures grown 7 days under various concentrations of cobalt, copper and zinc were also determined. Carbohydrate content of the tested alga also declined in manner dependent on the metal concentration exist in the medium, but the inhibitory effect of the three tested metals were not pronounced as on protein content. The results obtained in Fig. 4 shows that the three tested metals initiated the total carbohydrates accumulation at the culture supplemented by $10^{-8} \mathrm{M}$. It is worth to mention that high concentrations of the three tested metals did not reduce the total amount of carbohydrates. The increased total carbohydrate accumulation following metals was accompanied by decrease in Fathi et al. (2005) reported that the higher doses severely attenuate chlorophyll synthesis coupled with severe drop in protein resulting in increased carbohydrates. From another point of view, Torres et al. (1998) demonstrated that algae Cylindrothica fusiformis produce carbohydrate as a defense mechanism against copper toxicity in stationary phase when cells are exposed to $0.5 \mathrm{mg} \mathrm{Cu} \mathrm{L}^{-1}$.

Figure 5 clearly shows that the total free amino acids of Chlorella vulgaris gradually increased with increasing metals concentration. The most pronounced stimulation was detected at the culture supplemented with $10^{-7} \mathrm{M}$ copper in comparison to the other tested metals. However, increasing copper concentration more than $10^{-7} \mathrm{M}$, the total amount of free amino acids partially reduced. On the other hand, cobalt and zinc also stimulated the biosynthesis of the total free amino acids, but the stimulatory effect is less than that obtained with copper. Omar (2002) showed that zinc at low concentrations increased total amino acid contents, however, decreased it at high concentrations. Generally, the accumulation of amino acids in response to metals concentrations may lead to the assumption that suppressed protein biosynthesis encouraged free amino acids accumulation, or may be due to some counteracting chelating mechanism against heavy metals toxicity (El-Sheekh et al., 2003; Osman et al., 2004; Fathi et al., 2005).

Algae are known to be able to accumulate heavy metals. They are able to eliminate metal ions from aquatic solutions in a short time by biosorption in uncomplicated systems, without any problems of toxicity. It is an important biochemical function of algae in the shaping of proper ecological relationships and interactions between organisms in the aquatic environment (Wilde and Benemann, 1993; Sandau et al., 1996; Bajguz, 2000).

The data of Fig. 6 performed that accumulation of cobalt, copper and zinc by Chlorella vulgaris cells were parallel to increasing the concentrations in the culture medium. Also, it can be seen that the tested alga Chlorella vulgaris accumulated an appreciable amounts of copper more than other that observed with cobalt and zinc. However, no significant difference was observed between each of cobalt and Zinc. It is known that the uptake of an element from the surrounding medium is seldom exactly proportional to the amount present in the water. The data of Fig. 7 shows that the bioaccumulation factors (the ratio of concentration of an element in dry biomass and in the surrounding medium) of the three tested metals were parallel also to 
Am. J. Environ. Sci., 6 (3): 230-237, 2010

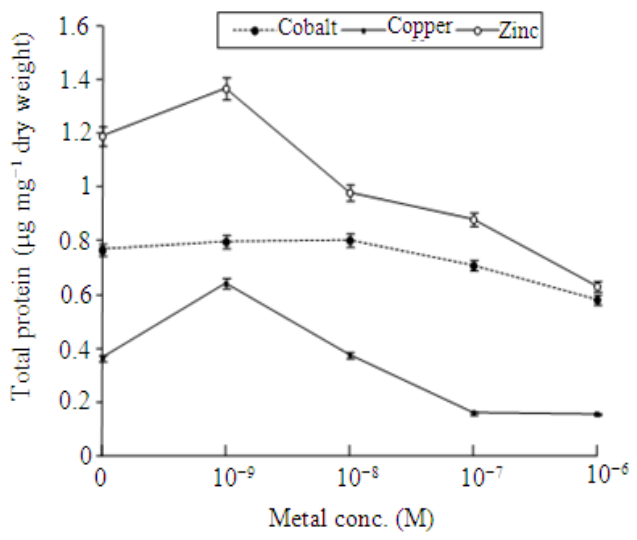

Fig. 3: Effect of various concentrations of cobalt, copper and zinc on total protein content ( $\mu \mathrm{g} \mathrm{mg}^{-1}$ dry weight) of Chlorella vulgaris after 7 days incubation period

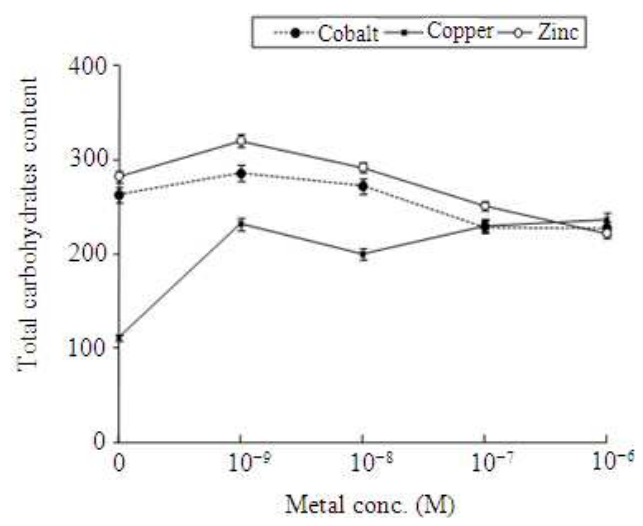

Fig. 4: Effect of various concentrations of cobalt, copper and zinc on total carbohydrates content ( $\mu \mathrm{g} \mathrm{mg}^{-1}$ dry weight) of Chlorella vulgaris after 7 days incubation period. Vertical bars indicate $\mathrm{SE}, \mathrm{n}=3$

increasing the concentrations in the culture medium. However, the bioacuumulation factor of copper is always higher than that of cobalt and zinc in all treatments. Metal accumulation by Chlorella vulgaris were shown to be in an order of $\mathrm{Cu}^{2+}>\mathrm{Co}^{2+}>\mathrm{Zn}^{2+}$.

The ability of microalgae to accumulate metals from aqueous solution is well-documented (Fathi and Falkner, 1997; Fathi et al., 2000; Giusti, 2001) as well as the possibility of using microbial biomass to remove metals from effluents (Macaskie, 1991; Hamdy, 2000). Algae take metals up both passively and actively. Some, such as $\mathrm{Pb}$ and $\mathrm{Sr}$, may be passively adsorbed by charged polysaccharides in cell wall and intracellular matrix (El-Sheekh etal., 2003; Osman et al., 2004;

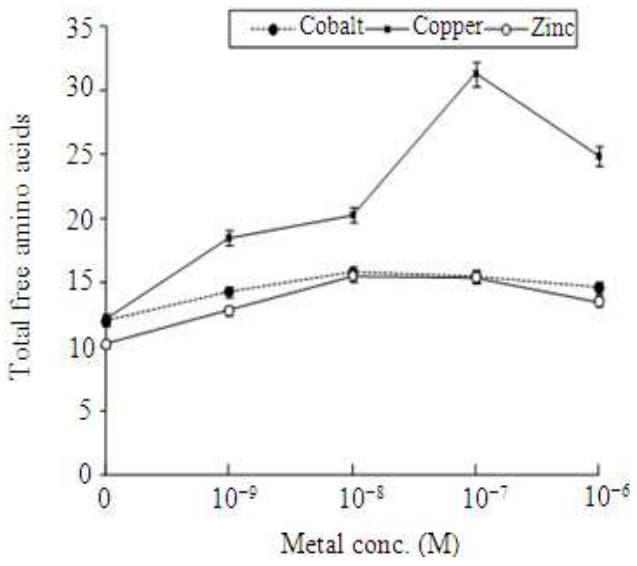

Fig. 5: Effect of various concentrations of cobalt, copper and zinc on total free amino acids ( $\mu \mathrm{g} \mathrm{mg}^{-1}$ dry weight) of Chlorella vulgaris after 7 days incubation period. Vertical bars indicate $\mathrm{SE}, \mathrm{n}=3$

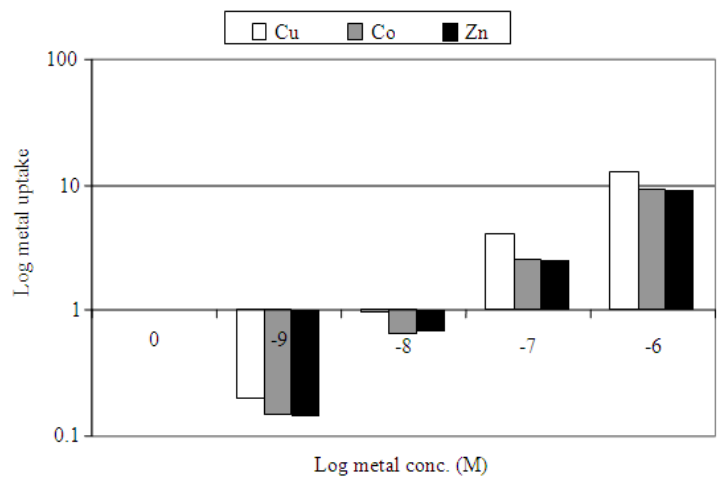

Fig. 6: Bioaccumulation of cobalt, copper and zinc ( $\mu \mathrm{g} \mathrm{mg}^{-1}$ dry mass) by Chlorella vulgaris after seven days growth period

Fathi et al., 2000; 2005). Other metals (e.g., Zn, Cd) are taken up actively against large intracellular concentration gradients. On the other hand, Barbara and Michael (1994) reported that the phenomenon of metal accumulation by microbial cells is quite complex, two principal mechanisms to adsorption on to the surface of the cell and a slower, active uptake into the cytoplasm. As passive biosorption mainly depends on binding to functional surface ligands the cell wall structure is most important for rapid metal ion uptake. Hamdy (2000) reported that metal uptake dependent on the type of biosorbant, with different accumulation affinities towards the tested elements and the amount of metal uptake increased steeply by increasing the weight of the biomass. Fathi et al. (2005) reported that the uptake of an element from the surrounding medium is seldom exactly proportional to the amount present in the water. 


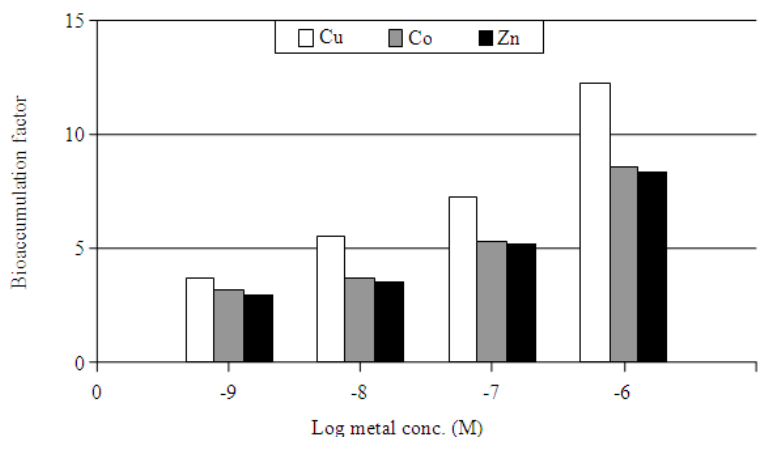

Fig. 7: Bioaccumulation factor of cobalt, copper and zinc by Chlorella vulgaris after seven days growth period

\section{CONCLUSION}

The inhibitory and stimulatory effects of either of the used heavy metals depend on concentration. Different organisms, however, have different sensitivities to the same metal and the same organisms may be more or less damaged by different metals. The uptake of an element from the surrounding medium is seldom exactly proportional to the amount present in the water. Different organisms, however, have different sensitivities to the same metal and the same organisms may be more or less damaged by different metals.

\section{ACKNOWLEDGEMENT}

We thank the Dean of Deanship of Scientific Research, King Faisal University and the Deanship members for financial support (Grant No: 10095).

\section{REFERENCES}

Akira, S., Q.V. Litiana, K. Norihide and M. Shigetoh, 2005. Evaluation of the sensitivity of marine microalgal strains to the heavy metals, $\mathrm{Cu}, \mathrm{As}, \mathrm{Sb}$, $\mathrm{Pb}$ and $\mathrm{Cd}$. Environ. Int., 31: 713-722. DOI: doi:10.1016/j.envint.2005.01.001

Albergoni, V., E. Piccinni and O. Coppellotti, 1980. Response to heavy metals in organisms. I. Excretion and accumulation of physiological and non physiological metals in Euglena gracilis. Comparat. Biochem. Physiol., 67: 121-127. DOI: 10.1016/0306-4492(80)90006-4

Anne, H.L.J., C. Marie, D. Veronique, B. Jean-Francois and L. Jean-Franc et al., 2006. Effect of copper sulphate treatment on natural phytoplanktonic communities. Aquat. Toxicol., 80: 267-280. DOI: 10.1016/j.aquatox.2006.09.004
Bajguz, A., 2000. Blockade of heavy metals accumulation in Chlorella vulgaris cells by 24-epibrassinolide. Plant Physiol. Biochem., 38: 797-801. DOI: 10.1016/S09819428(00)01185-2

Barbara, W. and W. Michael, 1994. Comparative studies of the heavy metal uptake of whole cells and different types of cell walls from Chlorella fusca. Biotechnol. Tech., 8: 227-232. DOI: 10.1007/BF00155412

Bates, S.S., A. Tessier, P.G.C. Campbell and J. Buffle, 1982. Zinc adsorption and transport by Chlamydomonas variabilis and Scenedesmas subspicatus (Chlorophyceae) grown in semi-continuous cultures. J. Physiol., 18: 521-529. DOI: 10.1111/j.0022-3646.1982.00521.x

Brooks, R.R. and M.G. Rumsby, 1965. The biogeochemistry of trace element uptake by some New Zealand bivalves. Limnol. Oceanogr, 10: 521-566. http://www.jstor.org/pss/2833449

Cecilia, R.M., M.L. Barsanti, V. Passarelli, V. Evangelista and V. Confortia et al., 2007. Effects of Chromium on photosynthetic and photoreceptive apparatus of the alga Chlamydomonas reinhardtii. Environ. Res., 105: 234-239. DOI: 10.1016/J.ENVRES.2007.01.011

De Filippis, L.F. and C.K. Pallaghy, 1994. Heavy Metals: Sources and Biological Effects. In: Algae and Water Pollution, Rai, L.C., J.P. Gaur and C.J. Soeder (Eds.). Schweizerbart, Stuttgart, pp: $31-77$.

De Filippis, L.F., R. Hampp and H. Ziegler, 1981. The effects of sub-lethal concentrations of zinc, cadmium and mercury on Euglena: 1-growth and pigments.-Z. Pflanzenphysiol, 101: 37-47.

Deng, L., Y. Su., Y. Sua, X. Wang and X. Zhua, 2007. Sorption and desorption of lead (II) from waste water by green algae Cladophora fascicularis. J. Hazard. Mater., 143: 220-225. DOI: 10.1016/J.JHAZMAT.2006.09.009

El-Naggar, A.H., M.E.H. Osman, M.A. Dyab and E.A. El-Mohsenawy, 1999. Cobalt and lead toxicities on Calothrix fusca and Nostoc muscorum. J. Union Arab Biol. Cairo, 7: 421-441.

El-Sheekh, M.M., A.H. El-Naggar, M.E.H. Osman and E. El-Mazaly, 2003. Effect of Cobalt on growth, pigments and the photosynthetic electron transport in Monoraphidium minutum and Nitzchia perminuta. Braz. J. Plant Physiol., 15: 159-166. DOI: 10.1590/S1677-04202003000300005

Fathi, A.A., A.M. El-Shahed, M.A. Shoulkamy, H.A. Ibraheim and O.M. Abdel Rahman, 2008. Response of Nile water phytoplankton to the toxicity Cobalt, Copper and Zinc. Res. J. Environ. Toxicol., 2: 67-76. DOI: 10.3923/rjet.2008.67.76 
Fathi, A.A. and G. Falkner, 1997. Adaptation to elevation of the concentration of the trace element copper during growth of Scenedesmus bijuga is reflected in the properties of the copper uptake system. J. Trace Microprobe Techn., 15: 321-333. http://cat.inist.fr/?aModele $=$ afficheN\&cpsidt $=2801131$

Fathi, A.A., 2002. Toxicological Response of a green alga, Scenedesmus Bijuga, to mercury and lead. Folia Microbiol., 47: 667-671. DOI: 10.1007/ BF02818669

Fathi, A.A., F.T. Zaki and A.A. Fathy, 2000. Bioaccumulation of some heavy metals and their influence on the metabolism of Scenedesmus bijuga and Anabaena spiroides. Egypt J. Biotechonl., 7: 293-307.

Fathi, A.A., F.T. Zaki and H.A. Ibraheim, 2005. Response of tolerant and wild type strains of Chlorella vulgaris to Copper with special references to Copper uptake system. Protistology, 4: 73-78. http://protistology.ifmo.ru/num4_1/fathi.pdf

Fisher, N. and J. Jones, 1981. Effects of Copper and Zinc on growth, morphology and metabolism of Asterionella japonica (Cleve). J. Exp. Mar. Biol. Ecol., 51: 37-56. DOI: 10.1016/00220981(81)90153-2

Giusti, L., 2001. Heavy metal contamination of brown seaweed and sediments from the UK coastline between the Wear River and the Tees River. Environ. Int., 26: 275-86. PMID: 11341296

Hamdy, A.A., 2000. Biosorption of heavy metals by marine algae. Curr. Microbiol., 41: 232-238. DOI: $10.1007 / \mathrm{s} 002840010126$

Jeffrey, S.W. and G.F. Humphery, 1975. New spectrophotometric equations for determining chlorophyll a, b and $\mathrm{c}$ in higher plants, algae and natural populations. Biochem. Physiol. Pflanzen., 167: 185-199.

Kuhl, A., 1962. The physiology of inorganic condensed phosphates in Chlorella. Vorlrag Bot. Hrsg. Deut. Botan. Ges. 1: 157-166.

Levy, J.L., J.L. Stauberand and D.F. Jolley, 2007. Sensitivity of marine microalgae to Copper: The effect of biotic factors on Copper adsorption and toxicity. Sci. Total Environ., 387: 141-154. DOI: 10.1016/J.SCITOTENV.2007.07.016

Lowery, O.H., N.J. Rosenbroug, A.F. Farr and R.J. Randall, 1951. Protein measurement with the folin phenol reagent. J. Biol. Chem., 193: 265-275. http://www.jbc.org/content/193/1/265.full.pdf+html

Macaskie, L.E., 1991. The application of biotechnology of the treatment of acid sites of biosorbents peat moss and Vaucheria and model substances alginic and humic acids. Environ. Sci. Technol., 33: $2252-2256$.
Moore, S. and W. Stein, 1948. Photometric ninhydrine method for use in the chromatography of amino acids. J. Biol. Chem., 17: 367-388. http://www.jbc.org/content/176/1/367.full.pdf+html

Mutlak, S.M., B.M. Salih and S.J. Tawfiq, 1979. Quality of Tigris river passing through Baghdad for irrigation. Tech. Bull., 8: 11-19.

Muwafq, H.M. and M. Bernd, 2006. Toxicity of heavy metals on Scenedesmus quadricauda (Turp.) de brebisson in batch cultures. Environ. Sci. Pollut. Res., 13: 98-104. DOI: 10.1065/espr2005.07.274

Nichol's, H.W., 1973. Growth media fresh water. In: Handbook of Physiological Methods Culture Method and Growth Measurements, Stein, J.R. (Ed.). Cambridge University Press, Cambridge, pp: 7-24.

Omar, H.H., 2002. Bioremoval of Zinc ions by Scenedesmus obliquus and Scenedesmus quadricauda and its effect on growth and metabolism. Int. Biodeteriorat. Biodegrad., 50: 95-100. DOI: 10.1016/S0964-8305(02)00048-3

Osman, M.E.H., A.H. El-Naggar, M.M. El-Sheekh and E. El-Mazally, 2004. Differential effects of $\mathrm{Co}^{2+}$ and $\mathrm{Ni}^{2+}$ on protein metabolism in Scenedesmus obliquus and Nitzschia perminuta. Environ. Toxicol. Pharmacol., 16: 169-178. DOI: 10.1016/j.etap.2003.12.004

Pena-Castro, J.M., F. Martinez-Jeronimo and A. Esparza-Garc, 2004. Heavy metals removal by the microalga Scenedesmus incrassatulus in continuous cultures. Bioresour. Technol., 94: 219-222. DOI: 10.1016/j.biortech.2003.12.005

Prassad, D. and A. Prassad, 1987. Alteredaminolaevulinic acid metabolism bylead and mercuryin germinating seedlings of Bajra (Pennisetum typhoideum). J. Plant Physiol., 127: 241-249.

Rijstenbil, J.W., F. Dehairs, R. Ehrlich and J.A. Wijnholds, 1998. Effect of the nitrogen status on Copper accumulation and pools of metalbinding peptides in the planktonic diatom Thalassiosira pseudonana. Aquat. Toxicol., 42: 187-209. DOI: 10.1016/S0166-445x(97)00091-X

Rocchetta, I., V. Mazzuc and M.R. Carmen, 2006. Effect of chromium on the fatty acid composition of two strains of Euglena gracili. Environ. Pollut., 141: 353-358. DOI: 10.1016/j.envpol.2005.08.035

Roe, J.H., 1955. The determination of sugar in blood and spinal fluid with anthrone reagent. J. Biol. Chem., 212: 335-343. http://www.jbc.org/content/212/1/335.full.pdf+html 
Romera, E., F. Gonzalez, A. Ballestera, M.L. Blazqueza and J.A. Munoza, 2007. Comparative study of biosorption of heavy metals using different types of algae. Bioresour. Technol., 98: 3344-3353. DOI: 10.1016/J.BIORTECH.2006.09.026

Sandau, E., P. Sandau and O. Pulz, 1996. Heavy metal sorption by microalgae. Acta Biotechnol., 16: 227-235.

http://www3.interscience.wiley.com/journal/10759 2102/abstract

Torres, M., J. Goldberg and T.E. Jensen, 1998. Heavy metal uptake by polyphosphate bodies in living and killed cells of Plectonema boryanum (Cyanophyceae). Microbios, 96: 141-147.
Tripathi, B.N.I. and J.P. Gaur, 2006. Physiological behavior of Scenedesmus sp. during exposure to elevated levels of $\mathrm{Cu}$ and $\mathrm{Zn}$ and after withdrawal of metal stress. Protoplasma, 229: 1-9. DOI: 10.1007/s00709-006-0196-9

Wilde, E.W. and J.R. Benemann, 1993. Bioremoval of heavy metals by the use of microalgae. Biotechnol. Adv., 11: 781-812. PMID: 14538057 